\title{
Evaluation model of MOOC grade based on incidence matrix
}

\author{
Yafang Zhi* and Yizhi Wu \\ Guangzhou College of Technology and Business, Guangzhou, China
}

Keywords: MOOC, Calculation of grades, Traditional models, Matrix.

\begin{abstract}
Under the current situation that MOOC are highly valued, how to guide online students to learn through MOOC has become a research topic. The traditional score calculation model has some problems. This paper proposes a MOOC score calculation model based on incidence matrix. Compared with the traditional model, it is more reasonable and can effectively promote students' learning enthusiasm and reduce the phenomenon of sudden improvement in scores.
\end{abstract}

\section{Incidence}

The introduction Today, with the highly developed Internet, the trend of education globalization is more and more obvious. MOOC (Massive Open Online Courses) are not only the innovation of Internet applications, but also believed to trigger A revolution in higher education and social development[1].It has been called "the greatest revolution in education since the invention of printing". Due to the great difference between MOOC and traditional teaching mode, it is difficult to reflect the advantages of MOOC, if the traditional teaching mode is adopted as a single evaluation method.

\section{Longed for class}

At present, most famous universities in China have opened their courses for free on MOOC platforms, providing convenience for the majority of learners. Some colleges and universities, through credit bank[2] and other means, exchange credits between MOOC courses and traditional courses, so as to realize credit certification of online courses. This new teaching mode not only weakens the imbalance of teaching resources, but also has the effectiveness of formal courses.

At present, the curriculum of general elective courses in colleges and universities mainly includes the following ways: traditional lectures, MOOC lectures and handouts. Due to the influence of class hours, lectures cannot fully realize the educational purpose of general courses. The traditional teaching mode is the best in terms of curriculum setting and teaching effect. However, most schools cannot allow students to receive personalized general education courses due to the influence of class hours and teachers, and giving out lecture

\footnotetext{
* Corresponding author: 2813239724@qq.com
} 
notes completely loses the significance of general education courses. Therefore, on the whole, MOOC is the most effective way to realize general education. On the one hand, students can learn at any time and place, free from the limitation of time and space, and solve the problems of classroom, teachers and class hours. On the other hand, MOOC enables students to receive their favorite general education courses and enjoy personalized online course services to promote their autonomous learning ability. More and more universities are offering MOOC to students for general education grades, with more than half of the MOOC' audience, 52.1 percent, according to MOOC.

When MOOC is used by more and more colleges and universities as an auxiliary means of course setting, the evaluation of its achievements has become a subject worth studying. In the traditional teaching model[3]. the evaluation of education quality is usually realized through a single approach, which is determined based on the assumption that the mental development level and receptivity of the audience of the traditional teaching model are basically the same and the learning motivation is basically unified. However, the group of learners has undergone great changes in MOOC environment, and learners' knowledge and ability background and learning motivation show diversity, which also varies from grade to grade in the same university. Therefore, it would be inappropriate to use the traditional teaching model for performance evaluation. In addition, due to the development of network technology, all the learning behaviors of learners on MOOC platform will be recorded in various forms of data[4], which should be used as the basis for learners' performance evaluation.

Current, longed for courses platform result the method of payment by the investigation and study, found that is still adopts the traditional way of performance evaluation in the majority, by video course, course test, final test scores of the three grades of module according to certain proportion to calculate the final result (most of the proportion of $3: 3: 4$ ), and platform for class of learners' access, discussion, homework, reading, live, sign in and interaction between the course data is not used, some of these recorded data is completely can be used in the reaction students learning enthusiasm and learning effect at ordinary times, should also be reflected in the certificate of completion of the final course grade.

\section{The basic principle of incidence matrix}

There are many methods to evaluate the system scheme, but some of them have inherent shortcomings, such as the conjecture evaluation calculation method, which has some problems in the credibility of the evaluation results. Some evaluation methods, such as analytic hierarchy process and scenario simulation, are too complicated and difficult to be implemented.

Incidence matrix is a kind of systematic evaluation method combining qualitative evaluation and quantitative evaluation, which is suitable for the system engineering with multiple indexes to determine the performance [5].Through the weight factor of the performance index in the system, the advantages and disadvantages of each scheme are shown in an intuitive way.

In system engineering, the evaluation of the performance is mainly based on the evaluation of the performance indicators to complete. In the incidence matrix, the contribution of each performance index to the overall performance evaluation is different, which is reflected in the weight of the performance index. If the performance index is more important to the performance evaluation of the evaluation subject, the weight coefficient is larger; otherwise, the weight coefficient is smaller[6].

In the system where the weight of incidence matrix is $\left\{V_{i} \mid i=1,2, \cdots, n\right\}$, it is assumed that the first-level index system of system evaluation scheme is $\left\{x_{i} \mid i=1,2, \cdots, n\right\}$, and the 
corresponding weight is $\left\{V_{i} \mid i=1,2, \cdots, n\right\}$. It is required that the weight value of each index should be less than 1 , and the sum of the weight coefficient of ownership should be 1 .In other words, the following two conditions should be satisfied:

$$
\begin{gathered}
0<V<1, \quad i=1,2, \cdots, n \\
\sum_{i=1}^{n} V_{i}=1
\end{gathered}
$$

If the secondary evaluation system of the performance index in the incidence matrix is $\left\{x_{i j} \mid x_{i}=1,2, \cdots, n ; j=1,2, \cdots, m\right\}$, and the weight system is $\left\{V_{i j} \mid i=1,2, \cdots, n ; j=1,2, \cdots, m\right\}$, then it must meet the following conditions:

$$
\begin{gathered}
0<V_{i j} \leq 1, i=1,2, \cdots, n \\
\sum_{j=1}^{m} V_{i j}=1 \\
\sum_{i=1}^{n} \sum_{j=1}^{m} V_{i} \cdot V_{i j}=1
\end{gathered}
$$

If there are more layers of indicators in the evaluation system, so on.

\section{Application examples}

At present, the academic performance evaluation of MOOC in most universities still continues the traditional course evaluation mode, focusing on the final performance. Although the learning process has been evaluated, the evaluation of the learning process is far from enough in the form of MOOC. The result of traditional teaching mode is mainly the final exam. Some teachers or courses only look at the result of the final exam, but they do not evaluate the learning process. For traditional courses, the learning process is indeed difficult to measure, and some can only be evaluated based on attendance, which is obviously not very appropriate. In the case of MOOC the network has a wealth of powerful data that can be used to show the learning process of students, which should be used to evaluate the learning process of students and the performance of students in the course.

\section{Evaluation index system of MOOC courses (new performance evaluation model)}

MOOC is still a kind of course, but its form is in the form of the Internet, so the final course completion evaluation is still the same as the traditional course, mainly based on the students' completion scores, while the evaluation of the learning process can be evaluated through the network performance and the quality of the learning completion. Learning quality is composed of: Posting quality, unit homework completion, online video completion. The network performance mainly consists of the number of online discussions, check-ins, page views and course interactions. 


\section{Get weights by pair comparison method}

The key to the correct evaluation of the scheme is whether the incidence matrix can determine the proper weight of the evaluation index. Currently, there is no universally applicable method to determine the weight of the index, but there are two commonly used methods: a.j.klee method and pair by pair comparison method. Infusing loving method in comparison to the importance of the evaluation indexes for a kind of method, often used to make quantitative estimates typically for evaluation by the experts to determine the weight coefficient, and by the comparison method is according to the index to the importance of the qualitative analysis is a method of calculation is simple, clear, clear structure, no need to introduce other parameters, this paper longed for class performance evaluation index weight is obtained through by the comparison method. The basic algorithm is as follows: compare the price indicators of MOOC performance in pairs, with the more important ones getting 1 , the less important ones getting 0 , and the equally important ones getting 0.5 each.

Which index is more important to the performance is not determined by one person, but obtained through a variety of comprehensive methods, mainly through brainstorming, Delphi method and questionnaire survey. Through brainstorming method, we can get what factors should be the performance evaluation indicators, so as to get the first and second level of the MOOC performance evaluation system. Through questionnaire survey and Delphi method, the difference in the importance of performance evaluation indicators was obtained, and the weight coefficient was obtained. After brainstorming, the evaluation index system affecting MOOC performance is shown in table 1:

Table 1. Evaluation index system of mooc performance.

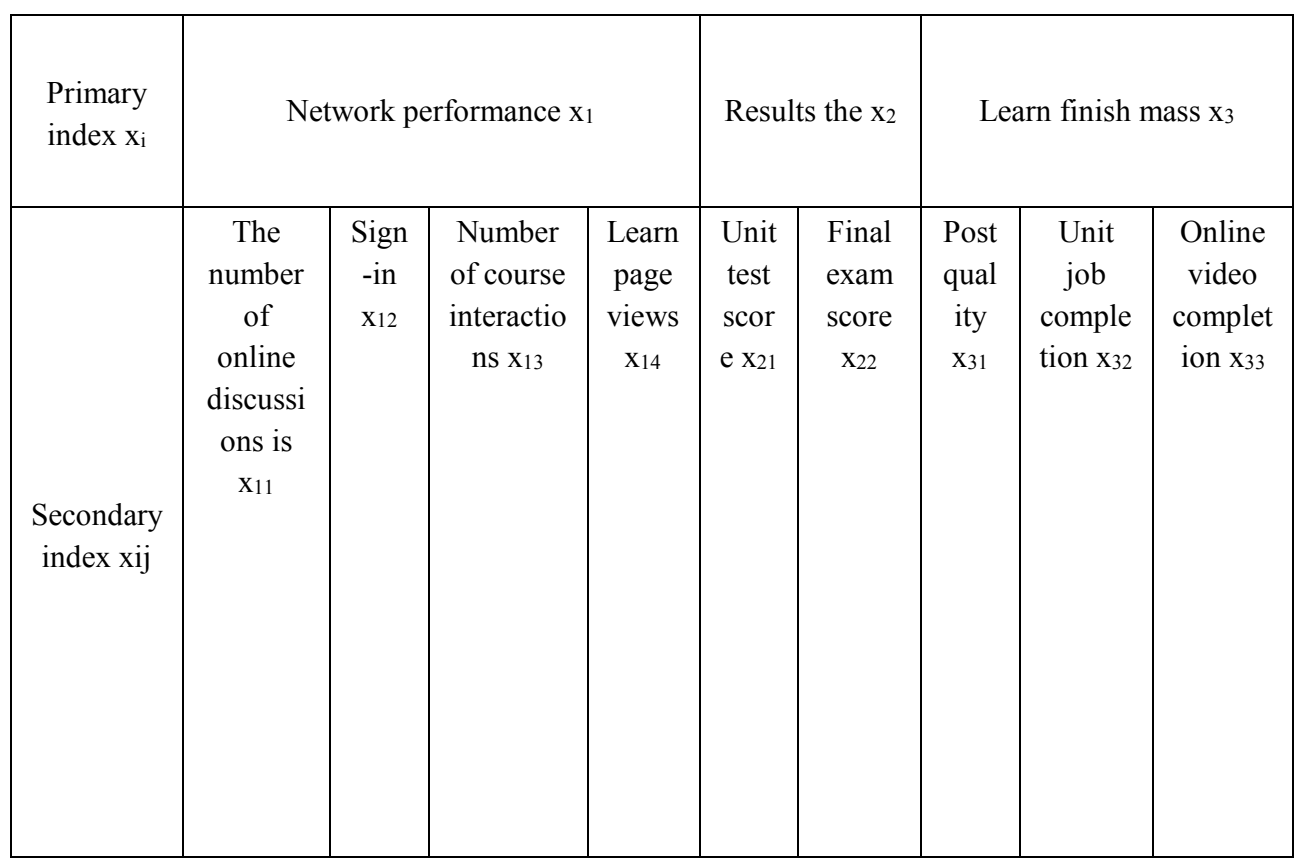

In level 1 assessment index system, as a course certificate of completion of the final standard, achievement is still one of the most important indicator, and the appraisal of students learning process is mainly through the network performance and learning to complete quality to reflect, through questionnaire and Delphi method, most of people think: mu class, student performance is as important as learning the quality of the finished at ordinary times, reflects the student learning process in the case of the position is the same. 
Therefore, a pair by pair comparison method is adopted to normalize the first-level indicators, and the weight of the first-level indicators is shown in table 2:

Table 2. Weights of each level index after normalization

\begin{tabular}{|l|l|l|l|l|l|}
\hline & $\begin{array}{l}\text { The network } \\
\text { performance }\end{array}$ & results & $\begin{array}{l}\text { Job } \\
\text { completion }\end{array}$ & $\begin{array}{l}\text { The cumulative } \\
\text { value }\end{array}$ & Weight value \\
\hline $\begin{array}{l}\text { The network } \\
\text { performance }\end{array}$ & 0 & 0.5 & & 0.5 & 0.166666667 \\
\hline Results & 1 & & 1 & 2 & 0.666666667 \\
\hline Job completion & & 0.5 & 0 & 0.5 & 0.166666667 \\
\hline
\end{tabular}

The second-level indexes under each first-level index were normalized by the pair-bypair comparison method, and the weight values of each second-level index were obtained as shown in table 3, table 4, and table 5:

Table 3. Weight of each index of network performance.

\begin{tabular}{|l|r|r|r|r|r|r|r|r|}
\hline The network performance & & & & & & & & Weight value \\
\hline Online discussion & 0 & 0 & 1 & & & & 1 & 0.166667 \\
\hline Sign in & 1 & & & 0 & 0 & & 1 & 0.166667 \\
\hline Number of course interactions & & 1 & & 1 & & 0 & 2 & 0.333333 \\
\hline Learning page views & & & & & & & & \\
\hline
\end{tabular}

Table 4. Weight of each index of performance.

\begin{tabular}{|c|c|c|}
\hline results & Unit test scores & The final exam \\
\hline & 0.5 & 0.5 \\
\hline
\end{tabular}

Table 5. Each index weight of learning completion quality.

\begin{tabular}{|l|r|r|r|r|r|}
\hline Learn the quality of completion & & & & The cumulative value & Weight value \\
\hline The quality of post & 0 & 0.5 & & 0.5 & 0.166667 \\
\hline Unit job completion & 1 & & 0.5 & 1.5 & 0.5 \\
\hline Online video completion & & 0.5 & 0.5 & 1 & 0.333333 \\
\hline
\end{tabular}

According to the traditional computer model, the final score of the student is: total score $=$ final score $* 0.4+$ online video completion $* 0.3+$ unit test score $* 0.3=64.1$ (score).

Based on the performance assessment model of MOOC based on incidence matrix, it can be seen from table 6 that the final score is 72.72.From the different final scores of the two calculation models, it can be seen that the incidence matrix proposed in this paper fully takes into account students' daily use, instead of just determining the final scores according to their examination results and their normal scores. The new calculation model is more reasonable, which can effectively promote students' learning enthusiasm, reduce the phenomenon of sudden score and improve students' learning initiative.

Correlation matrix method has the advantages of quick, concise, can be widely used in various business units and student achievement, performance appraisal, it is concluded that 
the results of the relatively objective and fair, for the weight of each index in the correlation matrix, should give full consideration to the importance and influence on the results, there should be a panel of experts to discuss the scores determine the weights.

Table 6. Evaluation model grade based on incidence matrix.

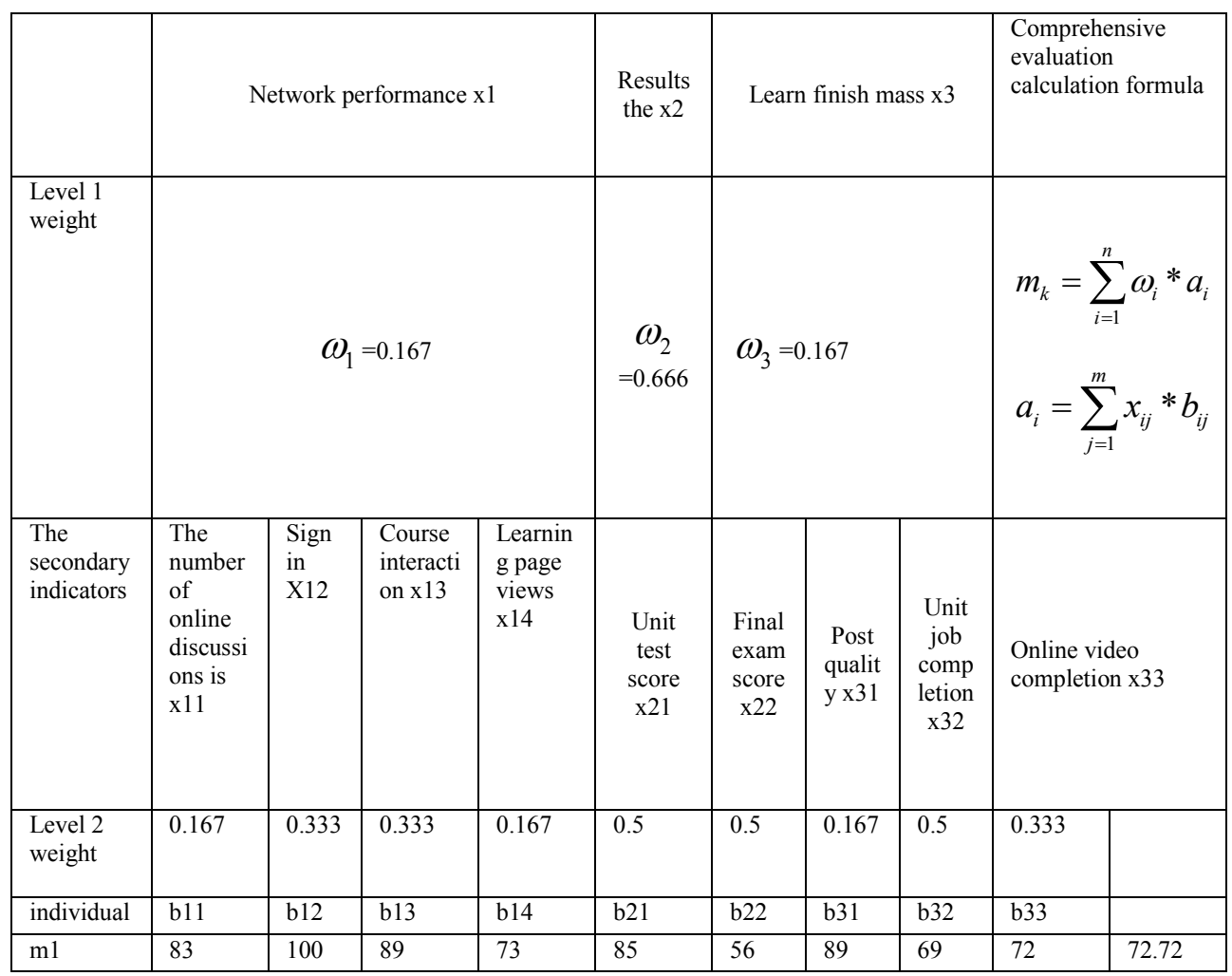

\section{Reference}

1. Downes S. New technology supporting informal learning [J] Journal of Emerging Technologies in Web Intelligence,2010,2(1):2733

2. Waldrop MM.Online learning:Campus 2.0 [J].Nature,2013,495(7440):160-163

3. Stein L A.Casting a wider net [J] Science,2012,338(6113):1422-1423

4. David rabelais.Independent growth brought about by complex structure: the reason for the rise of American higher education [J].Peking University education review, 2010, (3):24-29.

5. Azimi, A ; Bapat, R.B, Moore-Penrose inverse of theincidence matrixof a distance regular graph Linear Algebra and Its Applications, 15 August 2018, Vol.551, pp.92-103

6. Yu, Wy; Yan, CG; Ding, Zj; Jiang, CJ; Zhou, MC, Analyzing E-Commerce Business Process Nets viaIncidence Matrixand Reduction,IEEE Transactions On Systems Man Cybernetics-Systems, 2018 Jan, Vol.48(1), pp.130-141 